\title{
NEUROCOGNITIVE STATUS IN INDONESIAN HIV-INFECTED REPRODUCTIVE WOMEN
}

\author{
SARMA NURSANI LUMBANRAJA* \\ Fetomaternal Division, Department of Obstetrics and Gynecology, H. Adam Malik General Hospital, University of Sumatera Utara, Medan, \\ Indonesia. Email: snlumbanraja@gmail.com \\ Received: 18 December 2018, Revised and Accepted: 19 June 2018 \\ ABSTRACT \\ Objective: HIV-associated neurocognitive disorder (HAND) was emerging with the deficits inclusion of psychomotor, memory, attention, \\ and verbal fluency. This situation could increase the burden of an HIV-positive subject in daily activities, either the economic or social burden. \\ However, the cases were more likely isolated without exact prevalence data. \\ This study aims to find the prevalence of HIV-HAND in Indonesia.
}

Methods: This was an analytical research with cross-sectional design to assess neurocognitive status in reproductive age mothers who took regular ARVs for more than 6 months. Neurocognitive impairment in AIDS is diagnosed with the International HIV dementia scale. Data were analyzed using SPSS 19.0

Results: In this study, no subjects were diagnosed with had neurocognitive impairment. Only 1 of 29 subjects (3.4\%) with CD4>350/mm ${ }^{3}$ had slight psychomotor disorders.

Conclusion: This study showed that no subject with HIV infection in had dementia or neurocognitive impairment.

Keywords: Neurocognitive, HIV, AIDS.

(C) 2018 The Authors. Published by Innovare Academic Sciences Pvt Ltd. This is an open access article under the CC BY license (http://creativecommons. org/licenses/by/4. 0/) DOI: http://dx.doi.org/10.22159/ajpcr.2018.v11i10.24324

\section{INTRODUCTION}

In recent years, the HIV-related neurological disease has been increasingly recognized in resource-limited settings [1]. HIV infection infects the cells of immune system, destroying the cells, and impaired cellular functions [2]. Either the viral products or cytokines triggered had the toxic effect on the neurons [3]. The recruitment of other inflammatory cells such as macrophages and $\mathrm{T}$ cells amplified the neuron destruction, thus leading to neurological disturbances [4]. HIV infection often results in varying degrees of neurocognitive dysfunction [3]. The dysfunction included deficits of psychomotor, memory, attention, and verbal fluency [4].

HIV-associated neurocognitive disorder (HAND) was the idiom to describe the range of neurocognitive dysfunction associated with HIV infection. HAND refers to a spectrum of neurocognitive impairment that includes asymptomatic neurocognitive (ANA) impairment, mild neurocognitive disorder, and HIV-associated dementia and is diagnosed using neuropsychological testing and functional status assessments [5]. The spectrum of HAND is wide, so in 2007 the criteria of Frascati were established to distinguish three subclasses of increasing severity in terms of cognitive and functional status: ANA impairment, mild neurocognitive disorder, and HIV-associated dementia [5].

The level of neurocognitive dysfunction was not only caused by the infection itself but also the clinical, social, and psychological factors of HIV infection that impacted the dysfunction [6]. Sacktor et al. showed that the prevalence of neurocognitive impairment showed significant increment from 2008 to 2012 (p=0.048), in 2008 was 33\%, in 2009 was $25 \%$, in 2010 was $25 \%$, and in 2012 was $31 \%$ [7]. Although the incidence of neurocognitive impairment due to HIV infection was lowers, since the introduction of antiretroviral therapy, this impairment was still a significant burden to persons living with HIV infection. The prevalence data of HAND were more likely isolated without exact prevalence data. Therefore, this study aims to find the prevalence of the HAND in Indonesia.

\section{METHODS}

This was an analytical research with cross-sectional design to assess neurocognitive status in reproductive age mothers who took regular ARVs for more than 6 months. The study was conducted from June 2017 to November 2017. The study was conducted at the Department of HIV infection Haji Adam Malik hospital (as a referral center hospital in Sumatera). The population in this study was all HIV-positive reproductive age mothers who were planning for pregnancy. Samples were taken from the mother who visited Posyansus Haji Adam Malik hospital (as a referral center hospital in Sumatra).

This study gathered all women of reproductive age with HIV positive infections who came to take ARVs each month. If the patient did not come to take the medication as scheduled, the researcher would visit the patient to his or her home to explain about the study. All subjects were explained about informed consent and those agreed were included in the study. Subjects with malignancy or interrupted taking for medication were excluded from the study.

Initially, a short interview to acquire subject's identity was performed, and data regarding drug regimen used were obtained from medical record. Subsequently, the subject was taken to the clinical pathology laboratory of RS Haji Adam Malik for blood sampling of about $25 \mathrm{~mL}$. The patient was tested for HIV dementia questionnaire.

Neurocognitive impairment in AIDS is diagnosed with the International HIV Dementia Scale. When assessed from the total score in which the new dementia category was enforced with a total score of $>7.5$; in this study, it was shown that no subject had dementia or neurocognitive impairment. 
Table 1: Neurocognitive Impairment Based On Viral Load

\begin{tabular}{lllll}
\hline Neurocognitive & CD4 $\leq \mathbf{3 5 0} \mathbf{~ m m}^{\mathbf{3}}$ & $\mathbf{C D} \mathbf{>} \mathbf{3 5 0} \mathbf{~ m m}^{\mathbf{3}}$ & Undetected viral load & Detected viral load \\
\hline Normal (\%) & $8(21.6)$ & $29(78.4)$ & $3(8.1)$ & $34(81.9)$ \\
Abnormal & 0 & 0 & 0 & 0 \\
\hline
\end{tabular}

Data will be presented in the mean \pm standard deviation if the distribution is normal. If the distribution is not normal, the data will be presented in the quartile form. If the distribution is normal, the results obtained were analyzed using SPSS 19.0. This study is considered significant if the value of $\mathrm{p}<0.05$.

\section{RESULTS}

Neurocognitive impairment in AIDS is diagnosed with the International HIV Dementia Scale. In groups with $\mathrm{CD} 4 \leq 350 / \mathrm{mm}^{3}$, subjects with normal impairment or psychomotor were in the same proportion. In this study, overall no subjects were diagnosed with had a neurocognitive impairment (Table 1). Specifically, the author also did analyze the three aspects of neurocognitive in the questionnaire. Only 1 of 29 subjects (3.4\%) with $\mathrm{CD} 4>350 / \mathrm{mm}^{3}$ had slight psychomotor disorders. In the group with $C D 4 \leq 350 / \mathrm{mm}^{3}, 5$ of 8 subjects $(62.5 \%)$ subjected to memory impairment. Only 5 of 29 subjects $(17.2 \%)$ with CD $4>350$ / $\mathrm{mm}^{3}$ were subjected to memory impairment. In groups with $\mathrm{CD} 4 \leq 350$ / $\mathrm{mm}^{3}$, all subjects had normal construction. In the group with CD $4>350$ / $\mathrm{mm}^{3}, 2$ of 29 subjects $(6.9 \%)$ with $\mathrm{CD} 4>350 / \mathrm{mm}^{3}$ under construction disruption.

\section{DISCUSSION}

HIV remains more prevalent in the developing world. In 2012, the prevalence of neurocognitive impairment was 31\% [7]. This prevalence has been increasing since 2008 in which impacted the increment of social and economic burden [8]. Neurocognitive changes associated with HIV are typically subcortical, consisting of the triad of cognitive, behavior, and motor dysfunction [9]. Disorientation, mood disturbances, psychomotor slowing, and a decrease in attention, memory, and visuoconstructive coordination are part of the clinical picture [10]. While HIV therapy is often delayed, a heavy burden continues to occur in these settings due to the additional condition of opportunistic infections. Therefore, despite the success of combination antiretroviral therapy in controlling HIV infection as evidenced by decreased viral loads to undetectable levels, HAND have continued to affect HIV-infected populations [11]. In the 4-year study, Sacktor et al. showed that $77 \%$ of the 197 HIV+ individuals remained at their same stage, with $13 \%$ showing deterioration and $10 \%$ showing improvement in HAND stage [7].

HIV infection could induce innate and cellular immunity. In innate immunity activated circulating monocytes had a critical role, both for the introduction of HIV into the brain through transmigration across the blood-brain barrier in response to chemotactic signals expressed within the parenchyma, and establish infection within the brain perivascular [12]. The blood-brain barrier component, astrocytes, then produce and export non-structural proteins, HIV transcription factor, Rev (an HIV regulatory gene) and Nef (an early gene of HIV), all of which promote inflammation and neuronal damage [13].

Prevalences of ANA disorder, mild neurocognitive disorder, and HAD are $30-35 \%, 20-25 \%$, and $2-3 \%$, respectively. The CD4+ cell counts $<200$ cells $/ \mathrm{mm}^{3}$, age $>50$ years and low educational status were found to be risk factors for HAND [8]. In this study, when assessed from the total score in which the new dementia category was enforced with a total score of $>7.5$; in this study, it was shown that no subject had dementia or neurocognitive impairment. The recruitment of cellular $\mathrm{T}$ cells amplified the neuron destruction, thus leading to neurological disturbances which result in varying degrees of neurocognitive dysfunction [3], included deficits of psychomotor, memory, attention, and verbal fluency [4].
In this study, no subjects were diagnosed with had a neurocognitive impairment. Only 1 of 29 subjects (3.4\%) with CD4 $>350 / \mathrm{mm}^{3}$ had slight psychomotor disorders. In the group with $\mathrm{CD} 4 \leq 350 / \mathrm{mm}^{3}, 5$ of 8 subjects $(62.5 \%)$ subjected to memory impairment. Only 5 of 29 subjects $(17.2 \%)$ with $\mathrm{CD} 4>350 / \mathrm{mm}^{3}$ were subjected to memory impairment. In groups with $C D 4 \leq 350 / \mathrm{mm}^{3}$, all subjects had normal construction. In the group with $\mathrm{CD} 4>350 / \mathrm{mm}^{3}, 2$ of 29 subjects (6.9\%) with $\mathrm{CD} 4>350 / \mathrm{mm}^{3}$ under construction disruption. However, overall, the value was not statistically significant.

Similar to the descriptiveneurocognitive data in this study, a neurological disturbance was higher in subjects with lower CD4 and higher viral load. Wagner et al. in 38 HIV-positive subjects in antiretroviral therapy showed that the more severe HIV infection, the lower CD4+ and viral load. Using clinical ratings, global neurocognitive impairment was identified in 21 (55\%) participants, and multivariate analysis demonstrated a significant association between the more severe infection ( $p=0.028)[14]$. However, looking at the whole neurocognitive status, no subject in this study was classified to have the abnormality in the terms of using the HIV-dementia scale. The multicenter AIDS cohort study also showed no decline on several neuropsychometric tests in HIV patients and no difference was found with the seronegative individual [15]. Nevertheless, neurocognitive performance, laboratory measures, and neurological exams were performed every 6 months over a 42-month interval. Most (61\%) HIV patients remained stable, while $16.5 \%$ apparently improved neurocognitive status, and $22.7 \%$ declined.

Based on this study, the author recommend a continuous follow up. The consensus group agreed that screening for HAND should occur every 6-12 months in higher-risk patients or every 12-24 months in lowerrisk patients. More regular follow up must be considered for those who demonstrate clinical worsening of HIV disease, have a history of low nadir CD4 (e.g, <200 cells/ $\mu \mathrm{L}$ ), are not receiving ART; do not achieve virologic suppression despite cART, and develop new or worsened neurologic symptoms or signs [16].

\section{CONCLUSION}

This study showed that no subject with HIV infection had neurocognitive impairment.

\section{REFERENCES}

1. Malini H. HIV/AIDS stigma and discrimination among the general public in selected rural community, Kancheepuram District, India. Asian J Pharm Clin Res 2006;9:132-5.

2. Velmurugan S, Ali MA, Kumar P. Micro particulate drug carries a promising approach for the development of anti-HIV drugs. Int J Pharm Pharmaceutic Sci 2014;6:21-39.

3. González-Scarano F, Martín-García J. The neuropathogenesis of AIDS. Nat Rev Immunol 2005;5:69-81.

4. Gupta LK, Tripathi V. Chemokine receptors in HIV infection. Int J Pharm Pharmaceutic Sci 2012;4:69-72.

5. Antinori A, Arendt G, Becker JT, Brew BJ, Byrd DA, Cherner M, et al. Updated research nosology for HIV-associated neurocognitive disorders. Neurology 2007;69:1789-99.

6. Heaton RK, Franklin DR, Ellis RJ, McCutchan JA, Letendre SL, Leblanc S, et al. HIV-associated neurocognitive disorders before and during the era of combination antiretroviral therapy: Differences in rates, nature, and predictors. J Neurovirol 2011;17:3-16.

7. Sacktor N, Skolasky RL, Seaberg E, Munro C, Becker JT, Martin E, et al. Prevalence of HIV-associated neurocognitive disorders in the multicenter AIDS cohort study. Neurology 2016;86:334-40.

8. Ances BM, Ellis RJ. Dementia and neurocognitive disorders due to 
HIV-1 infection. Semin Neurol 2007;27:86-92.

9. Alfahad TB, Nath A. Update on HIV-associated neurocognitive disorders. Curr Neurol Neurosci Rep 2013;13:387.

10. Arya A, Sindhwani G. A review on the neural circuits in anxiety disorder. Asian J Pharm Clin Res 2016;9:26-31.

11. Clifford DB, Ances BM. HIV-associated neurocognitive disorder. Lancet Infect Dis 2013;13:976-86.

12. Churchill MJ, Wesselingh SL, Cowley D, Pardo CA, McArthur JC, Brew BJ, et al. Extensive astrocyte infection is prominent in human immunodeficiency virus-associated dementia. Ann Neurol 2009;66:253-8.

13. Chompre G, Cruz E, Maldonado L, Rivera-Amill V, Porter JT, Noel RJ Jr, et al. Astrocytic expression of HIV-1 nef impairs spatial and recognition memory. Neurobiol Dis 2013;49:128-36.

14. Wagner GA, Chaillon A, Liu S, Franklin DR Jr. Caballero G, Kosakovsky Pond SL, et al. HIV-associated neurocognitive disorder is associated with HIV-1 dual infection. AIDS 2016;30:2591-7.

15. Zipursky AR, Gogolishvili D, Rueda S, Brunetta J, Carvalhal A, McCombe JA, et al. Evaluation of brief screening tools for neurocognitive impairment in HIV/AIDS: A systematic review of the literature. AIDS 2013;27:2385-401

16. Heaton RD, Franklin D, Woods S, Collier A, Clifford D, Gelman B, et al. The Charter Group Prevalence and Predictors of Neurocognitive Decline Over 18 to 42 Months: A Charter Longitudinal Study. $19^{\text {th }}$ Conference on Retroviruses and Opportunistic Infections-Seattle. Western Australia; 2012. p. 246-8. 